\title{
Comparison and Analysis of Vertical Coherence in the Shallow Water of Two ocean region
}

\author{
${ }^{1}$ Sivakumar, V.G., ${ }^{2}$ V. Rajendran and ${ }^{3}$ R. Saranya \\ ${ }^{1}$ Department of ECE, Sathyabama University, Chennai, India \\ ${ }^{2}$ Department of Physics /ECE, SSN College Of Engineering, Chennai, India \\ ${ }^{3}$ Department of E\&I, Madha Engineering College, Chennai, India
}

Received 2013-05-06, Revised 2013-05-25; Accepted 2013-06-05

\begin{abstract}
Noise characteristics at shallow water is highly variable due to wave guide nature of the shallow water environment, reflection of noise from the bottom surface; due to biological activities and also due the sound speed in shallow water vary substantially. Thus noise field characterization is complex in shallow water. The ambient noise data was collected in the shallow water of Arabian Sea and the Bay of Bengal using the hydrophone suspended from the measuring platform. In this study, the comparison between vertical coherence of wind generated ambient noise in the shallow water of Arabian Sea and Bay of Bengal region is done. The noise spectra for both the region are also estimated. The relation between wind speed and noise at constant frequency is also found out.
\end{abstract}

Keywords: Acoustics, Coherence, Ambient Noise, Noise Spectrum, Bay of Bengal, Arabian Sea

\section{INTRODUCTION}

\subsection{Ambient Noise}

Surface generated noise is the prevailing noise of the ocean and its importance was identified in the earliest studies of ambient noise. It was originally considered to be a function of sea state, but later studies found that the noise correlated better with wind speed and it has since been known as "wind-dependent noise Douglas (2008). Ambient noise is the prevailing, unwanted background of sound at a particular location in the ocean at a given time. It does not include transient sounds such as the noise of nearby ships and marine organisms, or of passing rain showers. Ambient noise also excludes all forms of self-noise, such as the noise of current flow around the sonar.

The ambient noise field in the oceans is described by the spectral, spatial and temporal characteristics of sound generated by both natural and manmade sources. The Corresponding author: Sivakumar, V.G., Department of ECE, Sathyabama University, Chennai, India

detection of background noise is essential to enhance the signal to noise ratio of acoustic based underwater instruments. The measurement of the ambient noise helps us to determine the characteristics of sound and also the physical features of the ocean.

Study of ambient noise is very important for the design and development of underwater acoustic instruments such as Sonar, echo sounder and also for acoustic communications. Underwater ambient noise level is dominated by wind over a significant frequency compared to the other noise sources such as ship, rain, biological and human activity Ramji et al. (2008).

\subsection{Spectrum Estimation}

The main aim of the spectral estimation is to get the accurate estimate of power spectral density or the spectral information of the signal on the average basis. The Power Spectral Density (PSD), describes how the power (or variance) of a time series is distributed with frequency. Knudsen et al. (1948) spectra show the strong dependence 
of spectral power level with wind speed and sea states. This observed a decrease in wind/sea state dependency of underwater ambient noise below $500 \mathrm{~Hz}$. Further it was shown that there was no dependency below $100 \mathrm{~Hz}$ and the wind generated noise measurement shows self similar spectra between 100 to $10 \mathrm{kHz}$ Crocker (1998).

\subsection{Coherence}

Ambient noise in the ocean has been measured and studied over half a century. Even though vertical coherence of ambient noise in the deep ocean has been given considerable attention since 1960's, only few shallow water measurements have been reported in the frequency range of less than $2 \mathrm{kHz}$ Sanjana et al. (2009). A model for the spatial correlation of ambient noise in deep waters has been proposed by Walker and Buckingham (2012) who considered both surface and volume noise sources.

Coherence of noise is the degree to which the noise will be the same at two points located at a given distance in the sea. The vertical coherence of ambient noise in shallow water is seen to be stable since it is influenced by seabed characteristics and hence can be used for estimating geo-acoustic properties of the sea floor. The vertical coherence in the Bay of Bengal and the Arabian Sea region is found at constant wind speed and then comparison is made.

\section{MATERIALS AND METHODS}

\subsection{Data Collection}

The ambient noise data is recoded using the data acquisition system. A number of ambient noise data sets were collected in the Bay of Bengal and the Arabian Sea region for few months. Along with ambient noise, the wind speed data was also recorded. Other parameters like date, time, location, atmospheric temperature is also recorded. At both the location, two vertically spaced Omni-directional hydrophones were placed as shown in the Fig. 1. The depths of the hydrophones were 5 and 12 meter in both the regions.

During the period of data collection all the machinery in the boat and ships were switched off. Other pulse generating sensors like echo sounder if present in the boat are made inactive before data collection. Boat was anchored before the data collection to reduce the drift. The recording system was powered by battery. The wind speeds of collected data's ranges from 3.62 to $4.21 \mathrm{~m}$ $\mathrm{sec}^{-1}$ in the Bay of Bengal region and 0.95 to $10 \mathrm{~m} \mathrm{sec}^{-1}$ in the Arabian Sea region.

\subsection{Algorithm}

In this study, Welch periodgram is used for measuring the PSD. The Welch method consists of dividing the time series data into possibly overlapping segments, computing a periodogram of each segment and then averaging the PSD estimates. The Welch estimate of the power spectral density is given by Equation 1:

$$
\hat{\mathrm{S}}_{\mathrm{x}}^{\mathrm{W}}\left(\mathrm{w}_{\mathrm{k}}\right) \square \frac{1}{\mathrm{~K}} \sum_{\mathrm{m}=0}^{\mathrm{K}-1} \mathrm{p}_{\mathrm{x}_{\mathrm{m}}, \mathrm{M}}\left(\mathrm{w}_{\mathrm{k}}\right)
$$

\section{Where:}

$$
\begin{array}{ll}
\mathrm{P}_{\mathrm{x}_{\mathrm{m}}, \mathrm{M}}\left(\mathrm{w}_{\mathrm{k}}\right) & =\text { Power spectrum in } \mathrm{K}^{\text {th }} \text { segment } \\
\mathrm{K} & =\text { Number of overlapping segments }
\end{array}
$$

Welch's method is an improvement on the standard periodogram spectrum estimating method since it reduces the noise in the estimated power spectrum in exchange for reducing frequency resolution. Due to the noise caused by imperfect and finite data, the noise reduction from Welch's method is often desired.

Coherence can be calculated using the formula Equation 2:

$$
r(f)_{x y}=\frac{S_{x y}(f)}{\sqrt{S_{x x}(f) S_{y y}(f)}}
$$

where, $S_{x x}, S_{y y}$ auto spectral density functions.

The equation of the auto spectral density function is shown below Equation 3 and 4:

$$
\begin{aligned}
& S_{x x}=\int_{-\infty}^{\infty} R_{x x}(\tau) e^{-j 2 \pi f \tau} d \tau \\
& S_{y y}=\int_{-\infty}^{\infty} R_{y y}(\tau) e^{-j 2 \pi f \tau} d \tau
\end{aligned}
$$

where, $\mathrm{R}_{\mathrm{xx}}, \mathrm{R}_{\mathrm{yy}}$ auto correlation functions. The auto correlation functions show how quickly our ambient noise changes with respect to the time function Equation 5 and 6:

$$
\begin{aligned}
& R_{x x}=\frac{1}{T} \int_{0}^{T} x(t) x(t+\tau) d t \\
& R_{y y}=\frac{1}{T} \int_{0}^{T} y(t) y(t+\tau) d t
\end{aligned}
$$




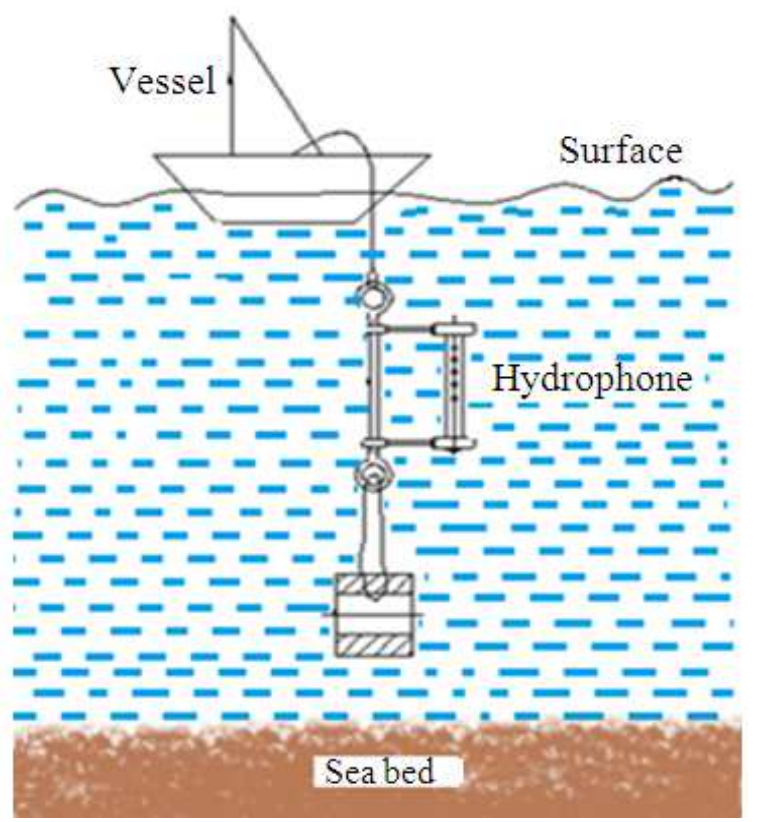

Fig. 1. Hydrophone setup

$\mathrm{S}_{\mathrm{xy}}$ is the cross spectral density function Equation 7:

$S_{x y}=\int_{-\infty}^{\infty} R_{x y}(\tau) e^{-j 2 \pi f \tau} d \tau$

where, $\mathrm{R}_{\mathrm{xy}}$ is the cross correlation function.

The cross correlation function shows how two hydrophone data's measurement varies with one another Equation 8:

$\mathrm{R}_{\mathrm{xy}}=\frac{1}{\mathrm{~T}} \int_{0}^{\mathrm{T}} \mathrm{x}(\mathrm{t}) \mathrm{x}(\mathrm{t}+\tau) \mathrm{dt}$

\section{RESULTS}

Analysis has been done to estimate the wind dependent ambient noise spectrum. Figure 2 shows the spectral estimation in the Bay of Bengal region for the wind speed of 3.62 and $4.21 \mathrm{~m} \mathrm{sec}^{-1}$. The figure clearly indicates that the noise level decreases with increase in frequency.

Using the below graph, comparison is done for wind speed Vs noise level at constant frequency. The result obtained is shown below. The blue line represents the noise level at $400 \mathrm{~Hz}$. The green line represents the noise level at $1200 \mathrm{~Hz}$. The red line represents the noise level at $2000 \mathrm{~Hz}$. From the Fig. 3 we can say that when the wind speed increases the noise level also increases with constant frequency.

Figure 4 shows the spectral estimation in the Arabian Sea region for the wind speed 3.34, 3.48, $3.30,3.08,4.63,4.30$ and $4.05 \mathrm{~m} \mathrm{sec}^{-1}$. Similar to the bay of Bengal graph shown in Fig. 2, in this estimation also the noise level decreases with increase in frequency for the same speed bay of Bengal region. For the same wind speed that is for the $3.62 \mathrm{~m} \mathrm{sec}^{-1}$, Bay of Bengal region noise level is around 120-128 $\mathrm{dB}$ but for Arabian Sea shallow water region the noise level is around 100-103 dB. The noise level difference mainly due to the seabed nature or any other background noise.

The pink line represents the noise level at $500 \mathrm{~Hz}$. The brown line represents the noise level at $1000 \mathrm{~Hz}$. The black line represents the noise level at $1500 \mathrm{~Hz}$. The green line represents the noise level at $2000 \mathrm{~Hz}$. The blue line represents the noise level at $2500 \mathrm{~Hz}$ and the red line represents the noise level at $3000 \mathrm{~Hz}$. From the Fig. 5 we can say that when the wind speed increases the noise level increases.

By comparing Fig. 3 and 5 we can say that the noise level in the Arabian sea region is less when compared to the bay of Bengal region.

Figure 6 shows the vertical coherence results for both real and imaginary in the Bay of Bengal region with the wind speed of $3.62 \mathrm{~m} \mathrm{sec}^{-1}$.

Figure 7 shows the vertical coherence results for both real and imaginary in the Arabian sea region for the same wind speed like in Bay of Bengal that is $3.62 \mathrm{~m} \mathrm{sec}^{-1}$.

Figure 8 shows the comparison of the real coherence results in the Arabian Sea region and the Bay of Bengal region for the wind speed of $3.62 \mathrm{~m} \mathrm{sec}^{-1}$. The blue line represents the real coherence in the Bay of Bengal region and the red line represents the real coherence in the Arabian Sea region.

Figure 9 shows the comparison of the vertical coherence results in the Arabian Sea region and the Bay of Bengal region for the wind speed of $3.62 \mathrm{~m} \mathrm{sec}^{-1}$. The blue line represents the real coherence in the Bay of Bengal region and the green line represents the real coherence in the Arabian Sea region The red line represents the imaginary coherence in the Bay of Bengal region and the black line represents the imaginary coherence in the Arabian Sea region. 
Sivakumar, V.G. et al. / American Journal of Applied Sciences 10 (6): 542-548, 2013

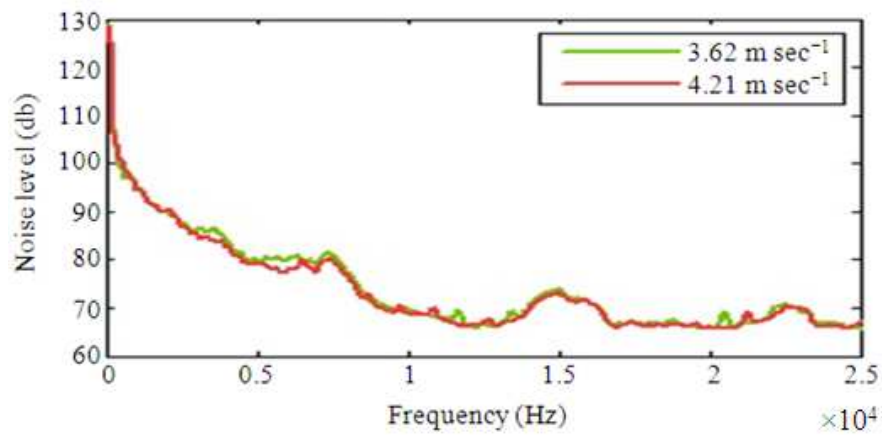

Fig. 2. Spectral estimation in bay of Bengal region

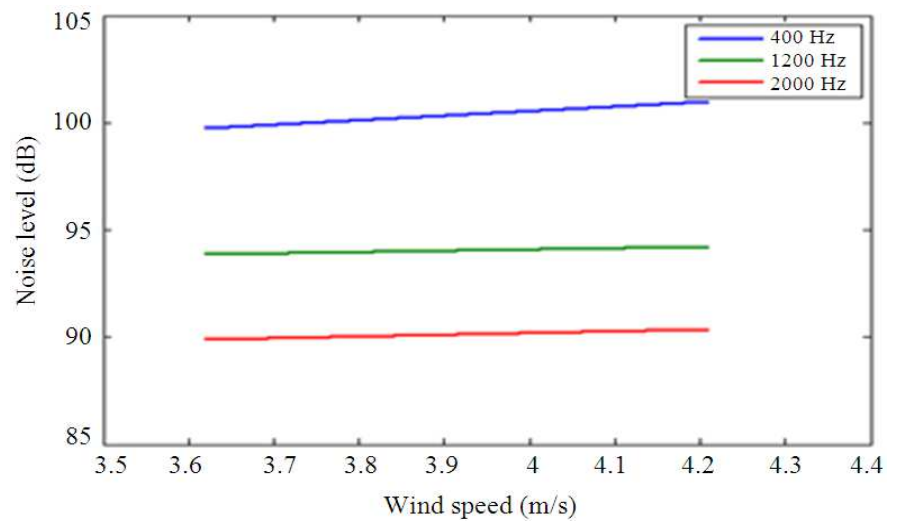

Fig. 3. Noise level at different frequency for varying wind speeds in bay of Bengal

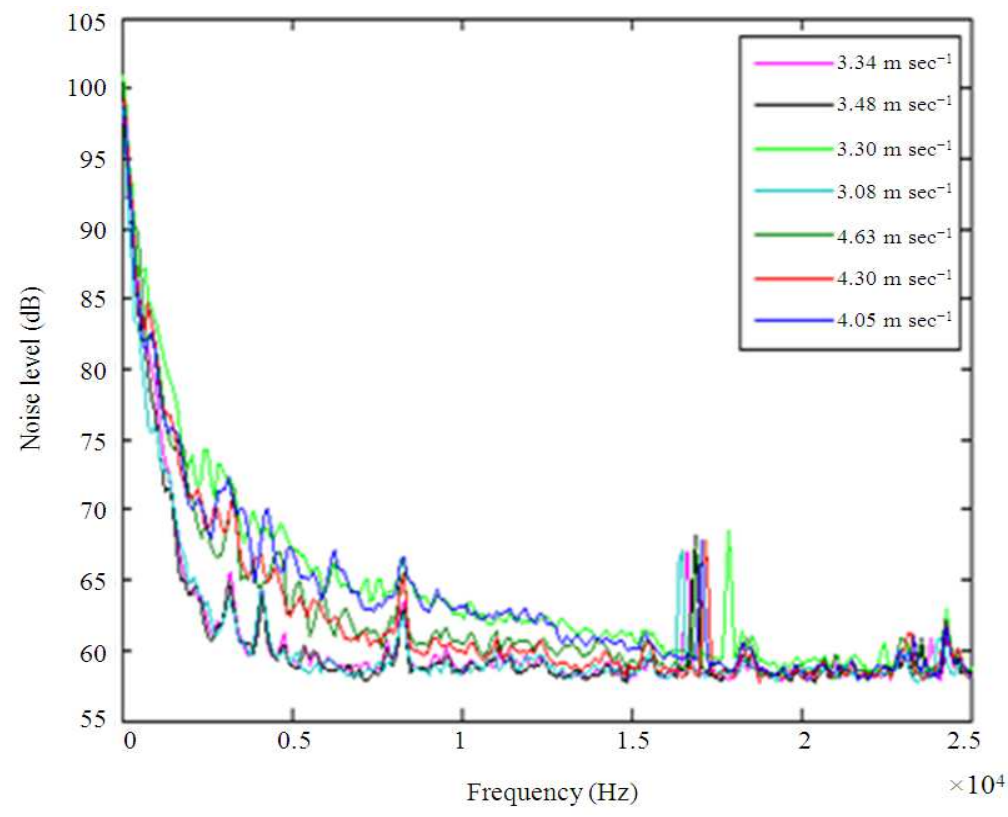

Fig. 4. Spectral estimation in Arabian sea region 
Sivakumar, V.G. et al. / American Journal of Applied Sciences 10 (6): 542-548, 2013

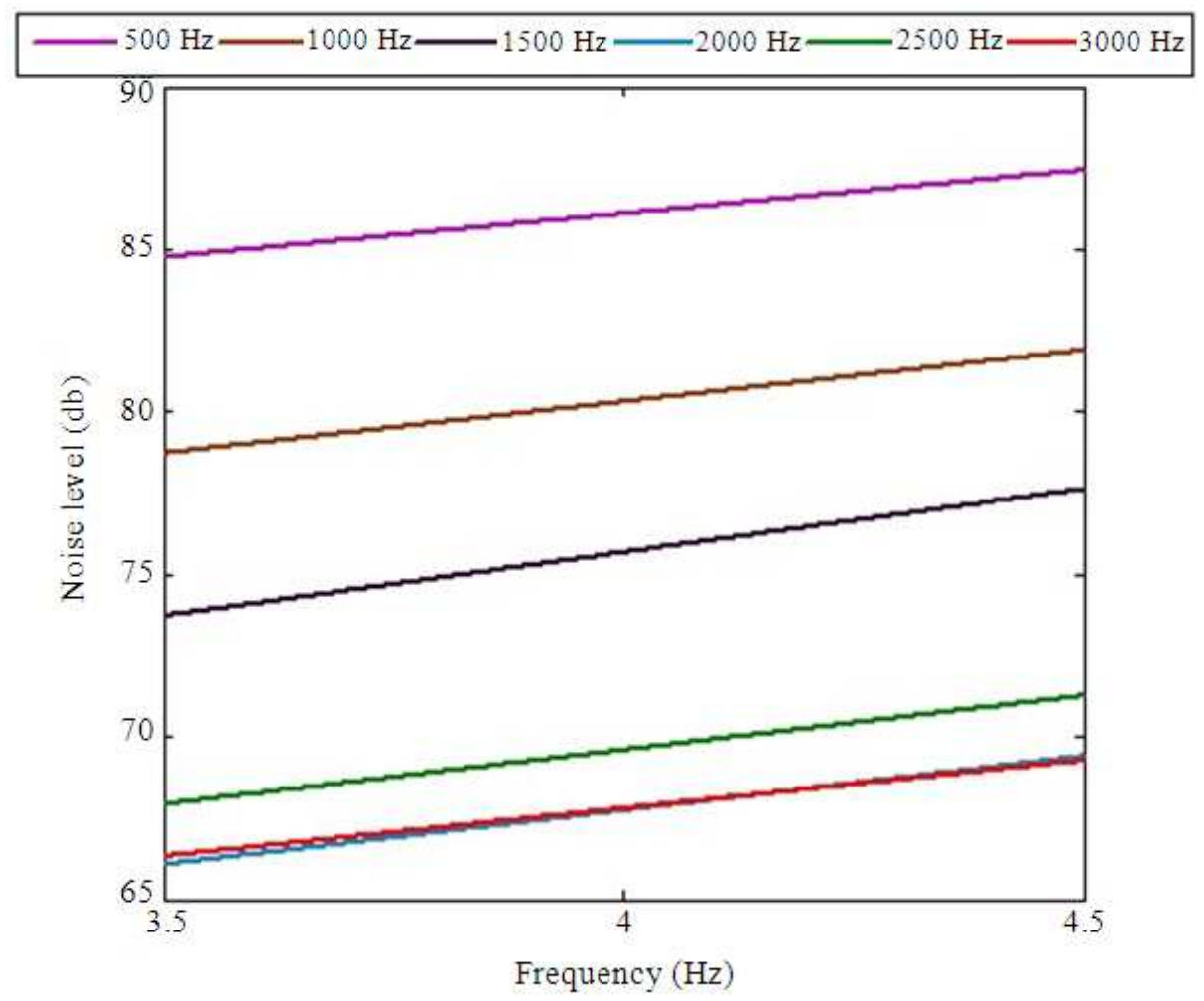

Fig. 5. Indicate that the relation between the wind speed Vs noise level at constant frequency

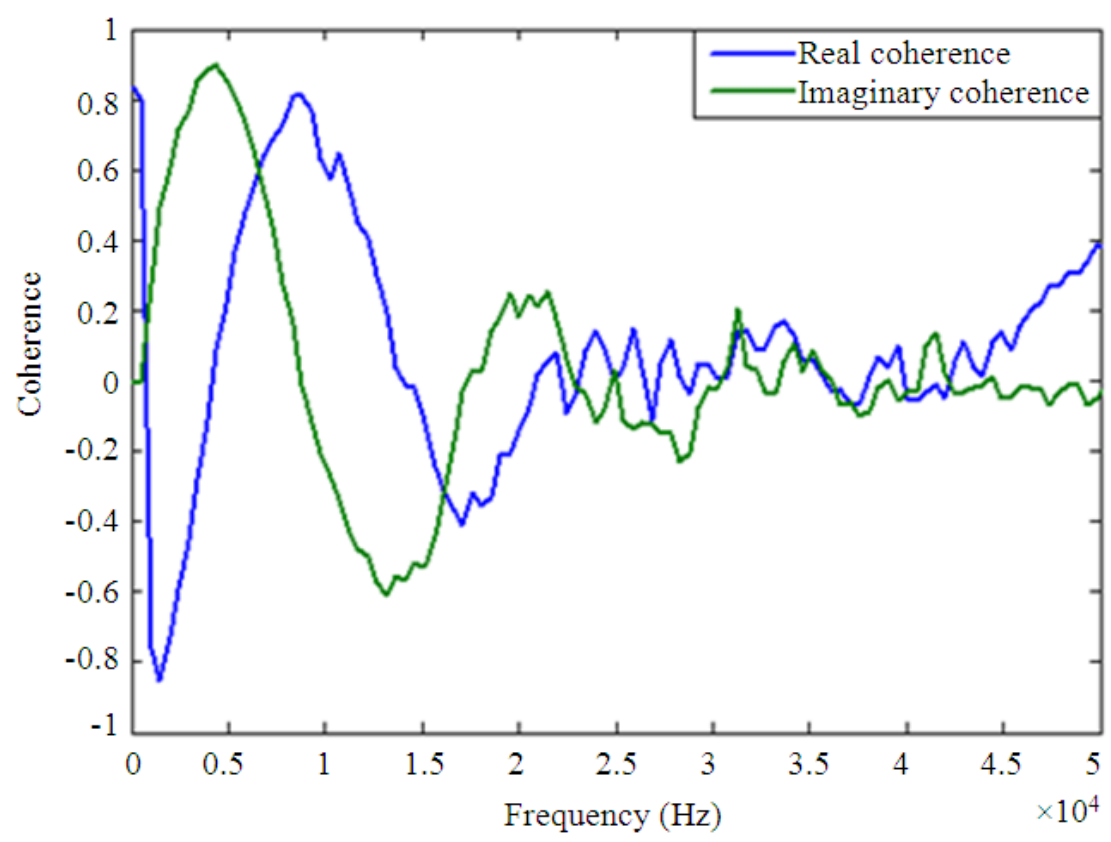

Fig. 6. Shows the real and imaginary coherence curve at windn speed of $3.62 \mathrm{~m}$ in Bay of Bengal 
Sivakumar, V.G. et al. / American Journal of Applied Sciences 10 (6): 542-548, 2013

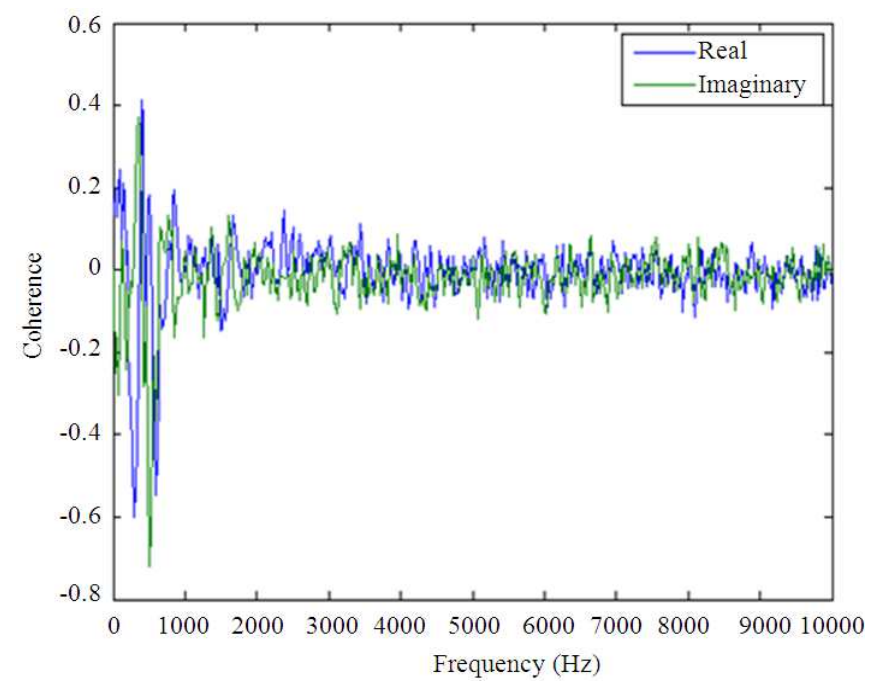

Fig. 7. Shows the real and imaginary coherence curve at wind speed of $3.62 \mathrm{~m} \mathrm{sec}^{-1}$ in Arabian Sea

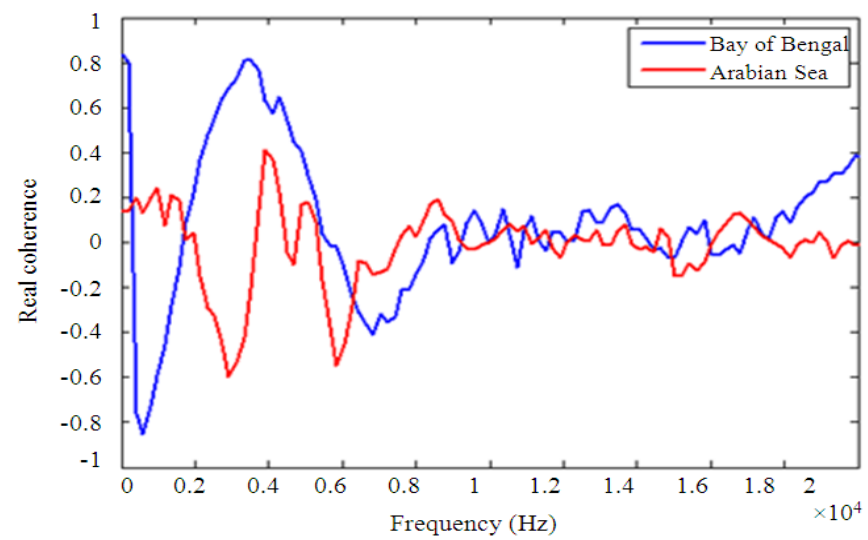

Fig. 8. Shows the real coherence curve at wind speed of $3.62 \mathrm{~m} \mathrm{sec}^{-1}$ in Arabian Sea and Bay of Bengal

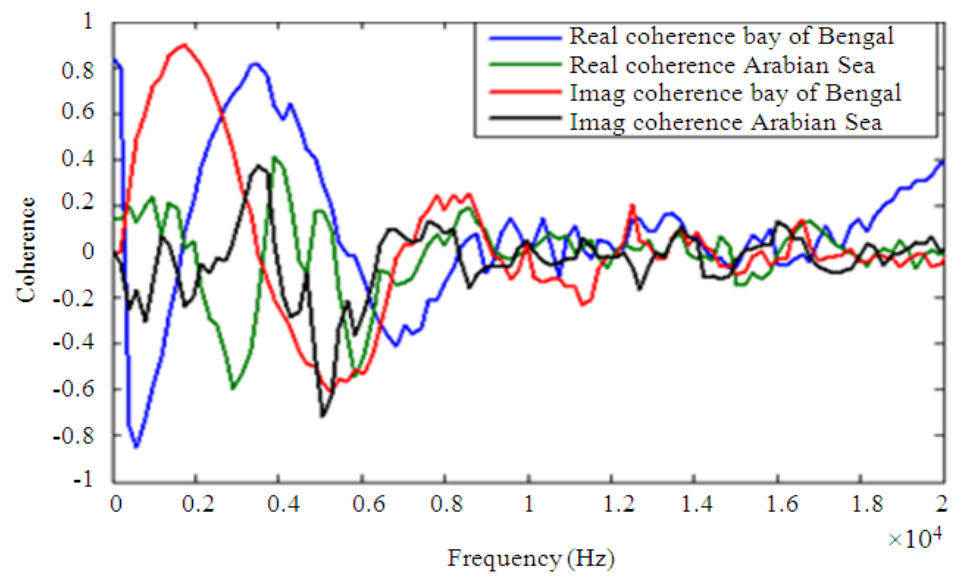

Fig. 9. Shows the real and imaginary coherence curve at wind speed of $3.62 \mathrm{~m} \mathrm{sec}^{-1}$ in Arabian Sea and Bay of Bengal 


\section{DISCUSSION}

In this proposed method compression of noise spectrum and coherence level were made between Arabian and Bay of Bengal ocean region. This analysis resulted that for the same wind speed at two different ocean region there is an variation in the noise spectrum level and coherence level. This result will be very useful for the further analysis to develop a model for the coherence between the two ocean region.

\section{CONCLUSION}

This study compares and analyzes the result of the spectrum level for the various wind speed and vertical coherence level for the two different shallow water sea region. There are many ways to extend this research. These experimental results could be used for further understanding of the effect of coherence level with different region of the sea. The following way in which this research can be continued they are: investigation of the seabed properties form the analysis of the coherence. This kind of application helps us to indicate how the coherence and seabed properties related with each other.

\section{REFERENCES}

Crocker, M.J., 1998. Handbook of Acoustics. 1st Edn., John Wiley and Sons, New York, ISBN-10: 047125293X, pp: 1461.

Douglas, H., 2008. Cato Defence Science and Technology Organisation. University of Sydney, Institute of Marine Science, Sydney, NSW 2006 Australia.

Knudsen, V.O., R.S. Alford and J.W. Emling, 1948. Underwater ambient noise. J. Marine Res., 7: 410-429.

Ramji, S., G. Latha, V. Rajendran and Ramakrishnan, 2008. Wind dependence of ambient noise in shallow water of Bay of Bengal. Applied Acoust., 69: 12941298. DOI: $10.1016 /$ j.apacoust.2007.09.001

Sanjana, M.C., G. Latha and Rajendran, 2009. Vertical coherence of ambient noise in shallow waters of Bay of Bengal. Proceedings of the International Symposium on Ocean Electronics, Nov. 18-20, IEEE Xplroe Press, pp: 110-114. DOI: 10.1109/SYMPOL.2009.5664160

Walker, S.C. and M.J. Buckingham, 2012. Spatial coherence and cross correlation of three-dimensional ambient noise fields in the ocean. J. Acoust. Soc. Am., 131: 1079-1086. 